\title{
Commentary: Teacher Candidates' Responses to Examining Personal Privilege: Nuanced Understandings of the Discourse of Individualism in Critical Multicultural Education
}

\author{
Marcelo Simões Mendes* \\ Association for Psychological Science (APS), Braganca Paulista, Brazil \\ Keywords: merit, levels of understanding, constructive cristicism, individuallity, distortions
}

\section{A Commentary on}

Teacher Candidates' Responses to Examining Personal Privilege: Nuanced Understandings of the Discourse of Individualism in Critical Multicultural Education by Whiting, E. F., and Cutri, R. M. (2019). Front. Educ. 4:111. doi: 10.3389/feduc.2019.00111

\section{OPEN ACCESS}

Edited by:

Luiz Sanches Neto,

Federal University of Ceara, Brazil

Reviewed by:

Willian Lazaretti Da Conceição, Federal University of Pará, Brazil

*Correspondence:

Marcelo Simões Mendes m_smendes@outlook.com

Specialty section: This article was submitted to Teacher Education,

a section of the journal

Frontiers in Education

Received: 29 June 2020 Accepted: 16 November 2020 Published: 03 December 2020

Citation:

Mendes MS (2020) Commentary: Teacher Candidates' Responses to

Examining Personal Privilege:

Nuanced Understandings of the Discourse of Individualism in Critical

Multicultural Education.

Front. Educ. 5:576388.

doi: 10.3389/feduc.2020.576388

\section{INTRODUCTION}

Even though the number of discourses involving equity increases in many domains of society, it is almost impossible to do not mention education as a tool-directly or indirectly-to contribute in this way. According to a recent global study that mapped disparities in education across many countries (Graetz et al., 2020), the relationship between education and health is a fundamental necessity to reduce inequalities.

Although the sounding contributions that quantitative studies demonstrate to analyze many factors associated with educational development and a decrease in inequality, some in-depth qualitative examinations are required. This commentary on Whiting and Cutri (2019) aims to discuss some aspects of education and meritocracy because I consider that their relationship could be disturbed ideologically.

According to Whiting and Cutri (2019), individualism is a condition of some privileges rooted in meritocratic societies. The study examined emergent discourses from 175 university students in their explanations of personal privilege. All representations of privileges were analyzed by their association with the discourse of individualism. In other words, the university students seem to recognize their privileges individually to a certain extent.

In my opinion, despite many contributions to understanding the structural inequality by critical multicultural education, Whiting and Cutri (2019) reinforce the relationship between privilege and individualism, whereas the merit is conceived as a terrible consequence. Also, is the criticality a property of critical multicultural education, or is it a fundamental thinking skill?

Even though meritocracy is associated with many speeches and actions that refer to individualism (Whiting and Cutri, 2019), the meritocracy's comprehension cannot totalize as synonymous with individualism. The comprehension of meritocracy implies many domains of human life. Some studies discuss the relationship between meritocracy, productivity, and inequalities (Livan, 2019), across reflections and actions since the economic area until debates in education and health fields. 
For instance, the study of Teklu (2018) presents a fundamental contribution because it includes morality as an axis of analysis. From the contributions of Teklu, many aspects could be considered starting points to reflect upon and develop the comprehension about the theme.

The first aspect is the definition of meritocracy and the principles that sustain its concept. The relationship between meritocracy and productivity is an economic fact, but the understanding of meritocracy cannot totalize in that conjuncture either. If it occurred, the meritocracy phenomenon itself could be annulled by essential phenomenological reasons.

According to Husserl's (1990) approach to phenomenology, the genuine sense of the principle is the constant permanence of being together to things. Then, the essence of meritocracy is the value of merit, and productivity is one way to attribute value to something hence produced and, for extension, to someone. It is true that seeking to increase productivity is associated with inequality, but many facets constitute this assumption.

As a digression, when Aristotle (2017) affirmed that some knowledge is more important than others, the philosopher demonstrated the necessary essential structure of the human soul. Only in this inequality structure-essentialistically conceivedthat the development and the merit can be achieved.

Thus, the productivity is not placed on the same plan of the merit, even recognizing the profound connection between both. The assumption of value in productivity could be higher than the merit of someone, but both terms' homogenization must preclude the value of merit.

According to Aristotle (2016), every substance is constituted by two elements: essence and accident. The essence is the central aspect that characterized someone and the hardest to changed. Already the accidents are variations by essence and, necessary, more prone to diversity. I advocate for such essentialist perspective in my comment.

The differences between essence and accidents are structurally necessary to qualify the development by the merit. Indeed, many ways regarding the relationships between essence and accidents

\section{REFERENCES}

Aristotle (2016). Methaphysics. Indianapolis, IN: Hackett Publishing Company. Aristotle (2017) De anima. Indianapolis, IN: Hackett Publishing Company.

Graetz, N., Woyczynski, l., Wilson, K. F., Hall, J. B., Abate, K. H., Abd-Allah, F. et al. (2020). Mapping disparities in education across low and middle-income countries. Nature 577, 235-238. doi: 10.1038/s41586-019-1872-1

Husserl, E. (1990). The Idea of Phenomenology. Dordrecht: Kluwer Academic Publishers.

Livan, G. (2019). Don't follow the leader: how ranking performance reduces meritocracy. R. Soc. Open Sci. 6, 1-11. doi: 10.1098/rsos.191255

Morin, E. (2014). Complex thinking for a complex world - about reductionism, disjuntion and systemism. Systema 2, 14-22. doi: 10.17101/SYSTEMA.V2I1.257

Teklu, T. A. (2018). Meritocracy and inequality: moral considerations. Palgrave Commun. 4, 1-9. doi: 10.1057/s41599-017-0059-3 occurred, and many used to promote pain and violence from privileged ones against the diversity. Nevertheless, the structure cannot be confused or totalized with the characteristics that make up this structure.

Another point related to this issue and mentioned by Livan (2019) is about serendipity. The author affirmed the positive relationship between serendipity and the promotion of success. I consider that this mention is extremely worrisome and dangerous from an essentialist standpoint.

Even the serendipity may be associated with a kind of freedom-generally more perceived around the context of arts for example-, thus this association can distort the meaning and the value of the merit. That distortion could prompt to the banality of the merit as an essential concept.

From the example of discovered penicillin mentioned by Livan (2019), the last affirmation can be checked. If I-as the author that writes this comment-was on vacation in 1928 and on return to Fleming Lab, see the culture of micro-organisms, I probably would put the culture in the trash.

\section{FINAL CONSIDERATIONS}

In conclusion, the meritocracy is a complex phenomenon that, according to Morin (2014), could not be reduced to a simplifying paradigm. Some ways to simplifying the comprehension of this phenomenon have equated meritocracy with productivity and serendipity with success.

The consequences of this equivalence can be essentially and profoundly destructive. One of them is promoting subconditions of the possibilities and limitations of the capacities' individuals have based on their beliefs weakened and their agency compromised.

\section{AUTHOR CONTRIBUTIONS}

MM collaborated in the design, the concept of the article, essay, and final revision of the manuscript.

Whiting, E. F. and Cutri, R. M. (2019). Teacher candidates' responses to examining personal privilege: nuanced understandings of the discourse of individualism in critical multicultural education. Front. Educ. 4:111. doi: $10.3389 /$ feduc. 2019.00111

Conflict of Interest: The author declares that the research was conducted in the absence of any commercial or financial relationships that could be construed as a potential conflict of interest.

Copyright $\odot 2020$ Mendes. This is an open-access article distributed under the terms of the Creative Commons Attribution License (CC BY). The use, distribution or reproduction in other forums is permitted, provided the original author(s) and the copyright owner(s) are credited and that the original publication in this journal is cited, in accordance with accepted academic practice. No use, distribution or reproduction is permitted which does not comply with these terms. 